\title{
Arterial ${ }^{18} \mathrm{~F}$-NaF-uptake as a marker for vascular calcification activity. Can a little salt cut the sweet: a golden bullet to evaluate vascular mineralization?
}

\author{
Yannick Kaiser, $M D{ }^{a}$ and Hein J. Verberne, $M D, P^{b}$ \\ a Department of Vascular Medicine, Amsterdam UMC, University of Amsterdam, Amsterdam, \\ The Netherlands \\ b Department of Radiology and Nuclear Medicine, Amsterdam UMC, University of Amsterdam, \\ Amsterdam, The Netherlands
}

Received Mar 31, 2021; accepted Mar 31, 2021

doi: $10.1007 / \mathrm{s} 12350-021-02624-8$

See related article, pp. 1855-1866

In this issue of the Journal of Nuclear Cardiology, Bellinge and colleagues from the University of Western Australia have investigated the effect of vitamin- $\mathrm{K}_{1}$ and colchicine on vascular calcification activity in a randomized fashion. ${ }^{1}$ In 154 patients with diabetes mellitus and present coronary calcification, they demonstrate that treatment with vitamin- $K_{1}$ and/or colchicine did not lead to a reduction in vascular calcification activity, as measured with ${ }^{18} \mathrm{~F}$-sodium fluoride $\left({ }^{18} \mathrm{~F}-\mathrm{NaF}\right) \mathrm{PET} / \mathrm{CT}$. In fact, ${ }^{18} \mathrm{~F}-\mathrm{NaF}$ uptake in both the aorta and coronary arteries did not statically change after the 3-month treatment period in all groups. The authors are to be congratulated on performing this well-matched, doubleblind, placebo controlled $2 \times 2$ factorial trial, evaluating promising therapies that distinctly target the inflammatory and osteogenic pathways which are deemed to contribute to vascular mineralization.

Editorial to The effect of Vitamin-K1 and Colchicine on Vascular Calcification Activity in subjects with Diabetes Mellitus (ViK$\mathrm{CoVaC}$ ); A double-blind $2 \times 2$ factorial randomized controlled trial.

Funding YK was supported by the Netherlands Heart Foundation CVON 2017-20: generating the best evidence-based pharmaceutical targets for atherosclerosis [GENIUS II]).

Reprint requests: Hein J. Verberne, MD, PhD, Department of Radiology and Nuclear Medicine, Amsterdam UMC, University of Amsterdam, Meibergdreef 9, Amsterdam1105 AZ, The Netherlands; h.j.verberne@amsterdamumc.nl

J Nucl Cardiol 2022;29:1867-9.

$1071-3581 / \$ 34.00$

Copyright (C) 2021 American Society of Nuclear Cardiology.
Although the extent of vascular calcifications is strongly related to cardiovascular risk, ${ }^{2}$ no treatment currently exists to halt or impair the process of vascular mineralization. ${ }^{3}$ Previous trials have shown inconsistent effects of drug therapy: statins for instance are described to either prevent, have no effect, or accelerate vascular calcification. However, these findings may reflect that intervention in various stages of the atherosclerotic disease process can affect the calcification process differently. ${ }^{4,5}$ When intervening before atherosclerosis develops, reducing the amount of apo-B containing lipid-laden particles may prevent calcification from occurring at all. Intervention in later stages may halt active inflammation, allowing encapsulation of established atherosclerotic plaque. On computed tomography (CT), this can translate to a higher calcium score (reflecting increased risk), even though highly calcified plaques have a lower risk of rupturing than low attenuation plaques.

To tackle this issue, researchers have looked at other methods to visualize the process of calcification. The use of ${ }^{18} \mathrm{~F}-\mathrm{NaF}$, originally developed as a bone tracer, has been extended to the field of atherosclerosis since the observation that vascular radiotracer accumulation often co-localizes with arterial calcifications. ${ }^{6} \mathrm{~F}$ $\mathrm{NaF}$ exchanges fluoride ions with hydroxyl ions on hydroxyapatite crystals and predicts progression of calcification, independent from baseline calcific burden. ${ }^{7,8}$ Moreover, previous studies have shown that ${ }^{18} \mathrm{~F}-\mathrm{NaF}$ preferentially adsorbs in areas of microcalcification, reflecting an earlier stage of the disease process which could still be amenable to medical therapy. ${ }^{9}$ However, important to note is that no trials have been able to 
demonstrate a reduction in vascular or valvular ${ }^{18} \mathrm{~F}-\mathrm{NaF}$ uptake after medical intervention yet.

${ }^{18} \mathrm{~F}$-fluorodeoxyglucose $\left({ }^{18} \mathrm{~F}\right.$-FDG) remains to date the only PET tracer that has been capable of showing a reduction from its baseline arterial wall uptake. Moreover, this observed reduction after treatment initiation generally aligns with clinical trial outcomes. For instance, the clinical benefit of statins, PCSK9-inhibitors, and pioglitazone were all paired with reductions of the ${ }^{18}$ F-FDG signal within a three- to fourmonth timeframe. ${ }^{10-12}$ Several negative clinical trial outcomes, such as for dalcetrapib, lipoprotein-associated phospholipase A2 inhibition, and P38 MAP kinase inhibitors, were also in line with the neutral effects on arterial wall inflammation evaluated by ${ }^{18} \mathrm{~F}-\mathrm{FDG} .{ }^{13-15}$ However, there are also important limitations associated with the use of ${ }^{18} \mathrm{~F}$-FDG, the most important ones being its non-specificity, and difficulty to assess coronary atherosclerosis due to the high myocardial background uptake. A more specific marker capable of assessing treatment effects over a short time period is therefore highly sought-after, but the promise of ${ }^{18} \mathrm{~F}-\mathrm{NaF}$ being such a marker still has to be delivered.

The finding of Bellinge and colleagues, as reported in this issue of the Journal of Nuclear Cardiology, that neither colchicine nor vitamin- $\mathrm{K}_{1}$ treatment reduces calcification activity in a timeframe of three months is an important addition to the ${ }^{18} \mathrm{~F}-\mathrm{NaF}$ literature, but does raise several questions. First, colchicine treatment has been shown to significantly decrease cardiovascular risk through inhibition of the NLRP-3 pathway. ${ }^{16}$ Hence, it is reasonable to imagine that colchicine treatment ultimately does ameliorate progression of calcification. For instance, colchicine has previously been shown to favorably modify coronary plaque. ${ }^{17}{ }^{18} \mathrm{~F}-\mathrm{NaF}$ uptake in atherosclerotic plaque is associated with vulnerable plaque characteristics, thus it would be expected that colchicine treatment can attenuate both in a similar fashion. This discrepancy may however be attributed to the difference in treatment duration between these studies: a year versus three months of follow-up. Although inhibition of inflammatory pathways may decrease osteogenic transformation in the long run, it could be that this transition is not visible within a period of three months. The absence of an effect of vitamin- $\mathrm{K}_{1}$ treatment on vascular ${ }^{18} \mathrm{~F}-\mathrm{NaF}$ uptake is interesting, as this directly interferes with the osteogenic pathway, thus is less likely to be caused by the relatively short treatment duration. Vitamin $\mathrm{K}$ is a vital component for the activation of matrix Gla protein, a potent inhibitor of tissue calcification. Nevertheless, extensive calcifications caused by vitamin $\mathrm{K}$ deficiency are mainly considered problematic in hemodialysis patients rather than diabetics, who were included in the current study.
Thus, whether vitamin- $\mathrm{K}_{1}$ treatment in a population with chronic kidney disease can attenuate vascular ${ }^{18} \mathrm{~F}-\mathrm{NaF}$ uptake remains to be answered.

Currently, there are several ongoing trials evaluating the effect of drug therapy on ${ }^{18} \mathrm{~F}-\mathrm{NaF}$ uptake. These studies mainly involve lipid lowering (NCT03233243, NCT03689946, NCT03051360) and modulation of osteogenesis (NCT02839044, NCT02917525, NCT02132026) in atherosclerosis and aortic valve stenosis. We have to wait for the outcome of these trials before we can adequately address the question whether ${ }^{18} \mathrm{~F}-\mathrm{NaF}$ is useful not only as a tool for the assessment of treatment effects but also if the changes (i.e., reduction) in ${ }^{18} \mathrm{~F}-\mathrm{NaF}$ uptake are related to improved patient outcomes.

\section{Disclosure}

The authors report no conflicts of interest.

\section{References}

1. Bellinge JW, Francis RJ, Lee SC, Vickery A, Macdonald W, Gan SK, et al. The effect of Vitamin-K1 and Colchicine on Vascular Calcification Activity in subjects with Diabetes Mellitus (ViK$\mathrm{CoVaC}$ ): A double-blind $2 \times 2$ factorial randomized controlled trial. J Nucl Cardiol 2021. https://doi.org/10.1007/s12350-021-02589-8.

2. Greenland P, Blaha MJ, Budoff MJ, Erbel R, Watson KE. Coronary calcium score and cardiovascular risk. J Am Coll Cardiol 2018:4:434-47.

3. Nakahara T, Dweck MR, Narula N, Pisapia D, Narula J, Strauss HW. Coronary artery calcification: From mechanism to molecular imaging. JACC Cardiovasc. Imaging 2017;5:582-93.

4. Achenbach S, Ropers D, Pohle K, Leber A, Thilo C, Knez A, et al. Influence of lipid-lowering therapy on the progression of coronary artery calcification: A prospective evaluation. Circulation 2002;9:1077-82.

5. Puri R, Nicholls SJ, Shao M, Kataoka Y, Uno K, Kapadia SR, et al. Impact of statins on serial coronary calcification during atheroma progression and regression. J Am Coll Cardiol 2015;65:1273-82

6. Derlin T, Richter U, Bannas P, Begemann P, Buchert R, Mester J, et al. Feasibility of 18F-sodium fluoride PET/CT for imaging of atherosclerotic plaque. J Nucl Med 2010;51:862-65.

7. Bellinge JW, Francis RJ, Lee SC, Phillips M, Rajwani A, Lewis JR, et al. 18F-Sodium fluoride positron emission tomography activity predicts the development of new coronary artery calcifications. Arterioscler Thromb Vasc Biol 2021;1:534-41.

8. Dweck MR, Jenkins WS, Vesey AT, Pringle MA, Chin CW, Malley TS, et al. 18F-Sodium fluoride uptake is a marker of active calcification and disease progression in patients with aortic stenosis. Circ Cardiovasc Imaging 2014;7:371-78.

9. Irkle A, Vesey AT, Lewis DY, Skepper JN, Bird JLE, Dweck MR, et al. Identifying active vascular microcalcification by $18 \mathrm{~F}$-sodium fluoride positron emission tomography. Nat Commun 2015;6:7495.

10. Tawakol A, Fayad ZA, Mogg R, Alon A, Klimas MT, Dansky H, et al. Intensification of statin therapy results in a rapid reduction in atherosclerotic inflammation: Results of a multicenter fluorodeoxyglucose- positron emission tomography/computed tomography feasibility study. J Am Coll Cardiol 2013;10:909-17. 
11. Hoogeveen RM, Opstal TS, Kaiser Y, Stiekema LC, Kroon J, Knol RJ, et al. PCSK9 Antibody alirocumab attenuates arterial wall inflammation without changes in circulating inflammatory markers. JACC Cardiovasc Imaging 2019;12:2571-3.

12. Mizoguchi M, Tahara N, Tahara A, Nitta Y, Kodama N, Oba T, et al. Pioglitazone attenuates atherosclerotic plaque inflammation in patients with impaired glucose tolerance or diabetes: A prospective, randomized, comparator-controlled study using serial FDG PET/CT imaging study of carotid artery and ascending aorta. JACC Cardiovasc Imaging 2011;4:1110-8.

13. Fayad ZA, Mani V, Woodward M, Kallend D, Abt M, Burgess T, et al. Safety and efficacy of dalcetrapib on atherosclerotic disease using novel non-invasive multimodality imaging (dal-PLAQUE): a randomised clinical trial. Lancet 2011;378:1547-59.

14. Tawakol A, Singh P, Rudd JH, Soffer J, Cai G, Vucic E, et al. Effect of treatment for 12 weeks with rilapladib, a lipoproteinassociated phospholipase A2 inhibitor, on arterial inflammation as assessed with 18F-fluorodeoxyglucose-positron emission tomography imaging. J Am Coll Cardiol 2014;1:86-8.

15. Emami H, Vucic E, Subramanian S, Abdelbaky A, Fayad ZA, Du $\mathrm{S}$, et al. The effect of BMS-582949, a P38 mitogen-activated protein kinase (P38 MAPK) inhibitor on arterial inflammation: A multicenter FDG-PET trial. Atherosclerosis2015;2:490-6.

16. Nidorf SM, Fiolet AT, Mosterd A, Eikelboom JW, Schut A, Opstal TS, et al. Colchicine in patients with chronic coronary disease. N Engl J Med 2020;383:1838-47.

17. Vaidya K, Arnott C, Martínez GJ, Ng B, McCormack S, Sullivan $\mathrm{DR}$, et al. Colchicine therapy and plaque stabilization in patients with acute coronary syndrome: A CT coronary angiography study. JACC Cardiovasc Imaging 2018;11:305-16.

Publisher's Note Springer Nature remains neutral with regard to jurisdictional claims in published maps and institutional affiliations. 